Marquette University

e-Publications@Marquette

$10-2016$

\title{
The Impact of Failing to Identify Suspect Effort in Patients Undergoing Adult Attention-Deficit/Hyperactivity Disorder (ADHD) Assessment
}

\author{
Paul S. Marshall \\ James B. Hoelzle \\ Marquette University, james.hoelzle@marquette.edu \\ Danielle Heyerdahl \\ Matthew W. Nelson
}

Follow this and additional works at: https://epublications.marquette.edu/psych_fac

Part of the Psychology Commons

\section{Recommended Citation}

Marshall, Paul S.; Hoelzle, James B.; Heyerdahl, Danielle; and Nelson, Matthew W., "The Impact of Failing to Identify Suspect Effort in Patients Undergoing Adult Attention-Deficit/Hyperactivity Disorder (ADHD) Assessment" (2016). Psychology Faculty Research and Publications. 228.

https://epublications.marquette.edu/psych_fac/228 
Marquette University

\section{e-Publications@Marquette}

\section{Psychology Faculty Research and Publications/College of Arts and Sciences}

This paper is NOT THE PUBLISHED VERSION; but the author's final, peer-reviewed manuscript. The published version may be accessed by following the link in the citation below.

Psychological Assessment, , Vol. 28, No. 10 (October 2016): 1290-1302. DOI. This article is (C) American Psychological Association and permission has been granted for this version to appear in $\underline{\mathrm{e}}-$ Publications@Marquette. American Psychological Association does not grant permission for this article to be further copied/distributed or hosted elsewhere without the express permission from American Psychological Association.

\section{The Impact of Failing to Identify Suspect Effort in Patients Undergoing Adult Attention- Deficit/Hyperactivity Disorder (ADHD) Assessment}

By: Paul S. Marshall

Department of Psychiatry, Hennepin County Medical Center, Minneapolis, Minnesota; James B. Hoelzle

Department of Psychology, Marquette University

Danielle Heyerdahl

Department of Psychiatry, Hennepin County Medical Center, Minneapolis, Minnesota Nathaniel W. Nelson

Department of Psychology, University of St. Thomas

\section{Abstract:}

This retrospective study examines how many adult patients would plausibly receive a diagnosis of attention-deficit/hyperactivity disorder (ADHD) if performance and symptom validity measures were not administered during neuropsychological evaluations. Five hundred fifty-four patients were 
extracted from an archival clinical dataset. A total of 102 were diagnosed with ADHD based on cognitive testing, behavior rating scales, effort testing, and clinical interview; 115 were identified as putting forth suspect effort in accordance with the Slick, Sherman, and Iverson (1999) criteria. From a clinical decision- making perspective, suspect effort and ADHD groups were nearly indistinguishable on ADHD behavior, executive function, and functional impairment rating scales, as well as on cognitive testing and key clinical interview questions. These results suggest that a significant percentage of those making a suspect effort will be diagnosed with ADHD using the most commonly employed assessment methods: an interview alone (71\%); an interview and ADHD behavior rating scales combined (65\%); and an interview, behavior rating scales, and most continuous performance tests combined (62\%). This research makes clear that it is essential to evaluate task engagement and possible symptom amplification during clinical evaluations.

\section{Keywords:}

ADHD, adult, malingering, effort tests, symptom validity tests

Adult attention-deficit/hyperactivity disorder (ADHD) is a challenging psychiatric diagnosis to make (Braun et al., 2004). No physical features, laboratory tests, or even cognitive deficits are by themselves pathognomonic for ADHD. The diagnosis revolves around a constellation of behavioral problems and cognitive deficits presented over time and manifested less often in the clinician's office than in nonmedical contexts, such as work or school. It is generally acknowledged that making the diagnosis of ADHD in adults is even more difficult than in children and adolescents (Greenfield, Ochs, \& Hechtman, 2002; McGough \& Barkley, 2004).

The number of individuals diagnosed and treated for ADHD has increased dramatically in recent years. For instance, the total number of prescriptions written for ADHD medications for patients ages 20-39 increased approximately 250\% between 2007 and 2011 (U. S. Drug Enforcement Administration, Office of Diversion Control, 2012). College students and other young adults are presenting for evaluation and diagnosis of ADHD in increasingly large numbers as awareness of the illness and benefits of being diagnosed with ADHD are better known.

The symptoms of ADHD are readily available in the popular press and on the Internet. As a consequence, patients can easily educate themselves so that they can effectively feign or exaggerate symptoms on behavior rating scales and in a clinical diagnostic interview to ensure they will be diagnosed with adult ADHD (Tan, Slick, Strauss, \& Hultsch, 2002).

Numerous simulation studies have convincingly documented individuals, college students in particular, can easily complete various ADHD behavior rating scales so that they look like they have ADHD. For example, no meaningful differences were found between students asked to simulate ADHD and patients diagnosed with ADHD in their completions of the ADHD Behavior Checklist-Current Scale (Fisher \& Watkins, 2008; Murphy \& Barkley, 1996; Quinn, 2003), the Barkley Adult ADHD Behavior Checklist Current and Childhood Symptoms Scale (Murphy \& Gordon, 2006; Sollman, Ranseen, \& Berry, 2010; Young \& Gross, 2011), and on five of the six Barkley Adult ADHD Self-Report Forms-IV symptom scores (BAARS-IV; Barkley, 2010; Williamson, Combs, Berry, Harp, Mason, \& Edmundson, 2014). Similar findings have also been reported in numerous other studies utilizing a wide array of ADHD behavior rating scales (Conners, Erhardt, \& Sparrow, 1999; DuPaul, Power, Anastopoulos, \& Reid, 1998; Fisher \& 
Watkins, 2008; Jachimowicz \& Geiselman, 2004; Harrison, Edwards, \& Parker, 2007; Harp, Jasinski, Shandera-Ochsner, Mason, \& Berry, 2011; Jasinski et al., 2011; Rios \& Morey, 2013; Tucha, Sontag, Walitza, \& Lange, 2009).

To date, only two studies have investigated how actual clinical patients referred for adult ADHD assessments and identified as making a suspect effort-based on failing performance validity tests (PVTs)-complete ADHD behavior rating scales. PVTs are rather easy cognitive tests designed to detect inadequate effort in testing. Suhr, Hammers, Dobbins-Buckland, Zimak, and Hughes (2008) and Marshall and colleagues (2010) both found no significant differences between patients making a suspect effort (based on failing at least one PVT) and credible patients diagnosed with ADHD based on their self-reported symptoms on standardized ADHD symptom scales.

It is abundantly clear that individuals can easily fake having ADHD by completing commonly used adult ADHD behavior rating scales in a manner that would suggest the presence of the disorder. Yet to date, only two symptom validity tests (SVTs) have been developed to identify individuals completing adult ADHD behavior rating scales in an invalid manner: the Clinical Assessment of Attention Deficit-Adult (CAT-A) Infrequency Scale (Bracken \& Boatwright, 2005) and the Infrequency Index for the CAARS-II, which is still being refined (Suhr, Buelow, \& Riddle, 2011). Despite the potential utility of these scales, only the CAT-A has been used to identify those making a suspect effort (Marshall et al., 2010).

In addition to obtaining key diagnostic information during a clinical interview and quantifying the severity of symptoms using behavior rating scales, cognitive testing may also facilitate accurate diagnosis. Research and theory has suggested that adults with ADHD will have problems on tests assessing effortful attention, inhibitory control, planning or set shifting, sustained attention, working memory, and self-regulation (Stefanatos \& Baron, 2007).

Problematically, numerous researchers have found many college simulators are able to successfully fake sustained attention problems on continuous performance tests (Booksh et al., 2010; Quinn, 2003; Sollman et al., 2010; Suhr et al., 2011). Similarly, ADHD simulators' performances also do not meaningfully differ from those with ADHD on select measures of response inhibition (Sollman et al., 2010; Suhr et al., 2008), working memory (Booksh et al., 2010; Suhr et al., 2008), and cognitive processing speed (Booksh et al., 2010; Sollman et al., 2010; Suhr et al., 2008). In summary, neuropsychological tests are as vulnerable to response distortion as behavior rating scales.

Given these results, it is not at all surprising that it is very difficult to identify adults who are exaggerating or feigning ADHD symptoms to secure that diagnosis when only conventional cognitive testing, clinical interviews, and ADHD behavior rating scales are used to make a diagnosis.

Furthermore, research has found that psychologists and psychiatrists are overconfident in their ability to detect behavioral and cognitive symptom exaggeration based on their review of a patient's cognitive test results and clinical histories. In fact, in two studies, neuropsychologists had a $100 \%$ error rate in identifying patients' malingering, though they were confident in their judgments (Faust, Guilmette, et al., 1988; Faust, Hart, Guilmette, \& Arkes, 1988).

The difficulties clinicians have in detecting patients faking ADHD is illustrated by Booksh and colleagues (2010). College students were asked to simulate ADHD symptoms during an assessment consisting of cognitive testing and behavioral rating scales. An independent psychologist was asked to judge 
whether a student was a simulator, a normal control subject, or a patient previously diagnosed with ADHD. All of the 111 study participants had completed the same five cognitive tests, the Wenders Utah Rating Scale (WURS) behavior rating scale, and a structured clinical interview. After reviewing all this information, the psychologist misclassified $44 \%$ of the students who had been asked to simulate ADHD symptoms as having ADHD and $11 \%$ of them as being normal.

Not only does research suggest that it is difficult to identify individuals engaging in response distortion and putting forth inadequate effort on cognitive measures, studies also indicate a large number of college students in particular are feigning or exaggerating ADHD symptoms. The percentage of students undergoing clinical ADHD assessments detected as making a suspect effort has varied significantly depending upon the specific criteria used to define suspect effort in each study.

PVTs are tests specifically designed to identify inadequate effort in cognitive testing. In general they are tasks that appear like standard neuropsychological tests measuring a cognitive ability but, in fact, are so simple that even individuals with significant cognitive deficits can perform perfectly or almost perfectly on them.

A larger percentage of students presenting for ADHD assessment have been identified as making a suspect effort when the criterion was failure on one PVT measure. Sullivan, May, and Galbally (2007) classified $47 \%$ (i.e., 10), Suhr et al. (2008) classified 31\% (i.e., 26), and Harrison and Edwards (2010) classified $18 \%$ (i.e., four) of their students as making a suspect effort based on failing solely the Word Memory Test (WMT; Green, 2003). However, failure on just one PVT is probably a very low criterion in identifying suspect effort as this commonly occurs in clinical patient populations. For example, Victor, Boone, Serpa, Buehler, and Ziegler (2009) found that $41 \%$ of credible clinical patients, with mixed acute neurologic and/or psychiatric diagnoses, failed one of several embedded PVT measures.

Three studies have used more conservative criteria in identifying those faking or exaggerating adult ADHD symptoms. Marshall et al. (2010) used six PVTs as well as one SVT, the CAT-A Infrequency Scale. They found $22 \%$ of 268 patients undergoing adult ADHD assessment exhibited suspect effort based on the conservative Slick, Sherman, and Iverson (1999) criteria for probable malingered neurocognitive dysfunction. Also, 12\% of college students undergoing assessment for ADHD (Harrison \& Edwards, 2010) and $10 \%$ of 513 college students seeking recommendations for academic accommodations and/or stimulant medications (Pella, Hill, Shelton, Elliott, \& Gouvier, 2012) made a suspect effort in their cognitive assessments based on the Slick criteria.

\section{Study Purpose and Rationale}

The purpose of this study is to examine several important questions related to exaggerating and feigning adult ADHD symptoms that prior research had not yet addressed. The first important question is establishing how frequently individuals exaggerating or feigning ADHD symptoms answer questions in a clinical interview in a manner that would support this diagnosis. The fact that individuals can complete behavior rating scales in a manner consistent with ADHD indicates they know the specific ADHD diagnostic criteria, as well as the other more general problems and specific symptoms adults with ADHD have. Even patients referred for ADHD assessment, who are not suspected of making an invalid presentation, commonly report having the core ADHD symptoms in clinical interviews. Barkley 
and Murphy (2011) found that almost 45\% of patients referred for ADHD assessment reported having sufficient symptoms to meet Diagnostic and Statistical Manual of Mental Disorders, Fourth Edition (DSM-IV) criteria, though they were subsequently not diagnosed with ADHD. However, a good clinical interview goes well beyond simply asking whether a patient experiences common adult ADHD related symptoms and problems.

Among other things, a comprehensive interview will rule out other possible psychiatric and neurologic conditions that can cause ADHD symptoms, clarify the onset and chronicity of ADHD symptoms, and determine whether these symptoms have had an adverse impact on the patient's function in their school, workplace, and personal relationships (Haavik, Halmøy, Lundervold, \& Fasmer, 2010; Murphy \& Gordon, 2006). A good interview will also ask about various factors that increase the likelihood of the patient having ADHD. For example, because ADHD heritability estimates range from 60\%-80\% (Freitag \& Retz, 2010), it is useful to ask whether any of the patient's first- or second-degree relatives have ever been diagnosed with ADHD. At this point, it is unknown how many people faking ADHD would provide such information. This is an important empirical question because an ADHD diagnosis is commonly made primarily, if not solely, based on a clinical interview.

The second important question is to evaluate the level of correspondence between the ADHD behavior rating scales completed by (a) patients making a suspect effort and their informants and (b) patients diagnosed with ADHD and their informants. At least five studies examining the correlations between adult self and informant reports on such scales have found a reasonably high level of agreement (i.e., correlations between .59 and .80). This is somewhat surprising given the well-documented finding that observers often provide discrepant ratings (Barkley, Knouse, \& Murphy, 2011). Nevertheless, it is conceivable self-informant report correlations might be significantly lower when a patient is exaggerating or feigning ADHD symptoms. Patients making a suspect effort may report higher levels of ADHD symptoms than their informants because the latter presumably report problems in a more objective and accurate manner. In fact, a very low correlation between self and informant reports on these scales might be a reason to further consider whether a patient is faking or exaggerating ADHD symptoms.

The third important question is to evaluate whether individuals making a suspect effort complete executive function behavior rating scales in a manner that supports an ADHD diagnosis. A more recent line of research has examined the ability of executive function related behaviors, rather than inattention and hyperactivity/impulsivity related behaviors, to diagnose this disorder. For example, Kessler et al. (2010) reported that executive function related behavioral problems (e.g., difficulties in organizing, planning ahead, prioritizing, completing tasks on time, and making mistakes) were identified as the most specific and consistent predictors of current DSM-IV adult ADHD diagnoses. In de Braek, Dijkstra, and Joelles (2011) also concluded executive functioning symptoms better differentiate patients with and without ADHD than inattention and hyperactivity-related symptoms.

Executive function related behavior rating scales such as the Barkley Deficits in Executive Functioning Scale (BDEFS; Barkley, 2011b) could be very helpful because, unlike traditional ADHD scales, it does not consist exclusively of behaviors that are used to diagnose ADHD and are readily found in the popular press and on the Internet. Hence, patients feigning or exaggerating ADHD symptoms may be 
significantly less likely to be able to complete the BDEFS in a manner consistent with those diagnosed with ADHD.

A fourth important question is whether patients making a suspect effort perform on cognitive testing in a manner similar to ADHD patients. Though studies asking college students to simulate ADHD in cognitive testing suggest they probably can, no research has examined the degree and frequency with which clinical patients making a suspect effort do this. Furthermore, studies to date have compared simulators' and ADHD patients' performances on only a few cognitive tests. It is not clear how actual patients exaggerating or faking ADHD symptoms would perform on many other cognitive tests of executive function abilities, working memory, and attention that are more challenging and, therefore, perhaps more sensitive to ADHD. Research has shown ADHD patients perform increasingly more poorly on tests as the number and level of complexity, time requirements, and processing speed increase (Hervey, Epstein, \& Curry, 2004).

The fifth question is how many actual patients making a suspect effort would be diagnosed with ADHD on the basis of a clinical interview alone, behavior rating scales alone, and cognitive testing alone. Perhaps even more importantly, given the manner in which clinicians vary in their assessment approaches, it would be helpful to know how many would be diagnosed with this disorder based on (a) the clinical interview and behavior rating scales and (b) the clinical interview, behavior rating scales, and cognitive testing if they were not identified as giving an invalid presentation.

\section{Method}

\section{Participants}

This archival study consists of 554 consecutive patients referred for an adult ADHD assessment in a general neuropsychological practice in the Department of Psychiatry at Hennepin County Medical Center (Minneapolis, Minnesota) between March 2008 and July 2014. Of these referrals, 428 were not disqualified by exclusion criteria. Patients were excluded if they (a) had any physical illness or neurological conditions (including head injuries), which might compromise central nervous system and cognitive function; (b) met diagnostic criteria for any organic mental disorder or any major psychiatric disorder (except depression or anxiety disorders); (c) had ever been diagnosed with a learning disability; or (d) exhibited an estimated Wechsler Adult Intelligence Scale-Fourth Edition (WAIS-IV) Full Scale IQ (FSIQ) score of less than 70. Some PVTs have questionable specificity rates in those identified as having mild intellectual disability (Dean, Victor, Boone, \& Arnold, 2008). Finally, patients were excluded if the frequency, number of years of use, and total amount used per week of alcohol, illicit substances, and/or prescription drugs were considered capable of causing impaired cognitive test performances.

Patients initially had been self-referred to other medical professionals and then were rereferred to our neuropsychology clinic. The great majority (approximately 80\%) were students referred from a large university mental health clinic. Approximately one quarter (i.e., 103) of the 428 patients reported having been previously diagnosed with ADHD; 34 of these 103 patients reported having been previously treated with ADHD medication. 
Study participants were physically healthy and faced with potentially receiving a diagnosis of ADHD that would probably be beneficial to them whether they truly had ADHD or not. One hundred sixty-six of the 428 patients (39\%) in this study were seen between March 2008 and February 2010. Many aspects of their performance on PVTs have been previously discussed (Marshall et al., 2010). The remaining 262 patients in the current study were seen between March 2010 and July 2014.

A significant percentage (i.e., 67\%) of the 428 patients reported experiencing a mood disorder. With regard to their primary psychiatric diagnoses, $12 \%$ were diagnosed with major depression, $22 \%$ with depression not otherwise specified (NOS), 2\% with dysthymia, 5\% with mood disorder NOS, and $12 \%$ with generalized anxiety disorder NOS. In addition, $14 \%$ of the patients had generalized anxiety disorder as a secondary psychiatric diagnosis. Thirty-seven percent of the patients were taking an antidepressant medication, while $6 \%$ were taking an anxiolytic medication. Finally, $10 \%, 6 \%$, and $3 \%$ of the patients reported using alcohol, marijuana, and cocaine, respectively. The frequencies of these psychiatric comorbidities are comparable with those described in other samples of ADHD patients (Barkley et al., 2008; Wilens et al., 2009).

The sample was predominantly male $(62 \%)$, and the average age was 26.38 (SD = 7.79; range $=17-55$ years). It is important to note that $79 \%$ percent of the sample was age 17-30. Nearly three quarters of the sample was Caucasian (79\%; African American 6\%; Hispanic, Asian, Native American; or other race $15 \%)$. Four percent of the sample had not graduated from high school, $10 \%$ had only graduated from high school, $47 \%$ had completed $1-3$ years of college, $38 \%$ had graduated from college, and $1 \%$ had graduated from high school and a vocational/technical school program. The overall mean years of education was $14.4(S D=1.97)$, with a range of 7th grade through graduate school. Two hundred ninety-eight (71\%) patients were attending college at the time they underwent ADHD evaluation. Only $4 \%$ of the patients had less than average intelligence based on estimated FSIQ scores. Seventy-three percent of the patients had high average or higher estimated FSIQ scores (mean estimated FSIQ = $117.67[S D=14.10]$; range $=71-149)$.

\section{Procedures}

Each patient completed a comprehensive neuropsychological evaluation consistent with the recommendations of a multimethod approach to the assessment of adult ADHD (Frazier, Demaree, \& Youngstrom, 2004; Weyandt \& DuPaul, 2013). It included the administration of numerous cognitive tests, an extensive semistructured clinical interview, behavioral observations, completion of self and informant ADHD behavior rating scales, and PVT testing. The semistructured clinical interview followed the lines of questioning recommended by Murphy and Gordon (2006). Patients prescribed ADHD medications had not taken them for a minimum of 24 or $48 \mathrm{hr}$ before testing for short-acting and longacting drugs, respectively (Nigg, 2005).

The cognitive tests used in these evaluations were administered according to standardized instructions by either a board-certified neuropsychologist or a trained and supervised clinical psychology doctoral student. The tests were administered in the same order to all patients. All 428 patients received at least the same core cognitive test battery that included the Vocabulary, Block Design, Digit Span, and Letter Number Sequencing subtests of the WAIS-IV (Wechsler, 2008a). The core battery also included the California Verbal Learning Test-II (CVLT-II; Delis, Kramer, Kaplan, \& Ober, 2000), Design Fluency, Color-Word Interference, and Tower Tests from the Delis-Kaplan Executive Function System 
(DKEFS; Delis, Kaplan, \& Kramer, 2001), Neuropsychological Assessment Battery (NAB) Number and Letters Test (White \& Stern, 2003), Paced Auditory Serial Addition Test (PASAT)-100 (Diehr et al., $\underline{2003}$ ), Salthouse Listening Span Test (Salthouse, 1994), Test of Variables of Attention

(TOVA; Greenberg, Kindschi, Dupuy, \& Corman, 1996), Dot Counting Test (Boone, Lu, \& Herzberg, 2002a), Sentence Repetition Test (Strauss, Sherman, \& Spreen, 2006), and b-Test (Boone, Lu, \& Herzberg, 2002b).

A subsample of the patients (i.e., 166, 39\%), assessed between the time frame March, 2008 to February 2010, were also administered the WAIS-IV Similarities, Comprehension, Symbol Search, and Coding subtests, Rey Complex Figure Test (Meyers \& Meyers, 1995), DKEFS Verbal Fluency Test, and Short Category Test (Wetzell \& Boll, 1991). Finally, the Wechsler Memory Scale-IV (WMS-IV) Spatial Addition Test (Wechsler, 2008b) was given to 337 of these patients in addition to the core test battery.

PVT measures were interspersed throughout the test battery because an individual's effort can fluctuate significantly over the course of an assessment (e.g., see Boone, 2009). The embedded and free standing PVT measures and their respective cutoff score for identifying suspect effort administered to all 428 study patients were the following: a score of 6 or less on the Reliable Digit Span score (Babikian, Boone, Lu, \& Arnold, 2006), two or more errors on the CVLT-II Forced Choice Recognition Test (Root, Robbins, Chang, \& van Gorp, 2006), a Sentence Repetition score of 10 or less (Schroeder \& Marshall, 2010), and less than 82.5\% correct for the immediate recognition, delay recognition, or recall consistency scores on the WMT (Green, 2003). In addition, the cutoff scores were an e-score of 14 or greater for the Dot Counting Test; an e-score of 70 or more, 2 or more commission errors, 2 or more $d$ errors, and time to completion of 550 or more seconds for the $b$ test; and total response time variability $>180 \mathrm{~ms}, 26$ or more omission errors, and 31 or more commission errors for the TOVA (Marshall et al., 2010).

All of the study patients completed the Barkley Adult ADHD Self-Report Forms for both current (adult) and childhood symptoms. Two hundred seventy-four patients completed an earlier version of these forms, the Barkley Adult ADHD Behavior Checklist Current and Childhood Symptoms Scales (Barkley AADHDSS; Barkley \& Murphy, 2006). One hundred forty patients completed the most recent version of these forms, the Barkley Adult ADHD Rating Scale-IV (BAARS-IV; Barkley, 2010). All of these Barkley Adult ADHD Self-Report forms consist of the 18 behavioral symptoms that comprise the DSM-IV ADHD criteria. The patient indicates whether they exhibit each behavior "rarely or never," "sometimes," "often," or "very often."

Whether the patient is endorsing experiencing symptoms consistent with ADHD is determined in two ways. First, the sum of the scores for all nine inattention symptoms and for all nine hyperactivity/impulsivity symptoms are compared with age and sex appropriate cutoff scores for the Barkley AADHDSS and the BAARS-IV, respectively. Second, each item that is reported as being exhibited "often" or "very often" counts as one symptom toward meeting the six out of nine symptoms necessary on either the inattention or hyperactivity lists to meet DSM-IV ADHD diagnostic criteria. Based on normative data, cut off scores for each of these variables have been identified indicating whether or not the patient's scores are consistent with the patient having ADHD (Barkley, 2011a; Barkley \& Murphy, 2006). 
In addition, 199 of the 428 patients completed the Barkley Deficits in Executive Functioning Scale-Short Form (BDEFS-SF; Barkley, 2011b) and 116 completed the Barkley Functional Impairment Scale-Short Form (BFIS-SF; Barkley, 2011c). The BDEFS requires the patient to report the degree to which they have impaired executive abilities. The BFIS-SF requires the patient to rate the degree to which they feel impaired with respect to their functioning in various environments (home, work, school) and with various individuals (family, friends). Both the BDEFS-SF and BFIS-SF were added to the assessment battery for research purposes only. They were not reviewed and had no role in making a diagnosis of ADHD.

Two supplemental ADHD symptom behavior rating scales were also given. The first was the nine behavioral symptoms, generally reflecting executive functions, that Barkley identified as being most effective in differentiating ADHD patients from community and clinical control subjects (Barkley, Murphy, \& Fischer, 2008, p. 437), which we will refer to as the Barkley Best Symptoms for Diagnosis-9 (BBSD-9) scale. Barkley concluded that an individual who endorses frequently experiencing at least six of these nine symptoms should be diagnosed with adult ADHD. The second supplemental scale is the CAT-A Infrequency Scale (Bracken \& Boatwright, 2005) that detects exaggeration or embellished symptom report. Only $1 \%$ of the CAT-A standardization sample and $6 \%$ of the combined clinical sample indicated that they "strongly agree" that they experience 3 of the 10 behaviors comprising the Infrequency scale. Therefore, the CAT-A Infrequency Scale responses were considered to suggest suspect completion of the behavior rating scales only if the patient endorsed experiencing at least 3 of the 10 behaviors "very often."

Finally, informants were asked to complete the Barkley AADHDSS (or BAARS-IV), BBSD-9, CAT-A, and BDEFS-SF behavior rating scales with regard to their observed behaviors. Of the 428 patients completing either the Barkley AADHDSS or BAARS-IV, a parent was the informant for $44 \%$ of the patients while $25 \%$ were a significant other, $18 \%$ were a very good friend, $10 \%$ were a spouse, and $3 \%$ were a sibling.

Patients were diagnosed as having adult ADHD if they met all four of the following criteria: (a) they completed behavior rating scales in a valid manner and scale scores were indicative of adult ADHD, (b) they reported significant impairment in at least one major setting (educational, occupational, home life/family function) during the clinical interview, (c) they reported having had some ADHD related symptoms impairing performance before age 16 that were not better accounted for by a comorbid disorder during the clinical interview, and (d) they had at least some valid cognitive testing results indicative of $A D H D$, at minimum one impaired sustained attention test score.

Exaggeration and feigning can occur in one of three patterns in neuropsychological assessments: false or exaggerated reporting of psychiatric and somatic symptoms, intentional poor performances on cognitive tests, or a combination of both symptom and cognitive deficit exaggeration (Larrabee, 2000; Van Dyke, Millis, Axelrod, \& Hanks, 2013). Patients were identified as having made a suspect effort in cognitive testing and/or in completion of the self-report ADHD behavior rating scales if they met the criteria proposed by Slick and colleagues (1999). Specifically, participants were identified as putting forth suspect effort if there was (a) failure on two separate PVT measures (e.g., the b Test and the Word Memory Test), or (b) failure on one PVT measure and invalid completion of behavior rating scales by the patient as indicated by a CAT-A Infrequency Scale score of 3 or higher. In their study of 
the effectiveness of four embedded PVTs, Victor et al. (2009) found that failure of any two embedded PVTs had a sensitivity of $83.8 \%$ and specificity of $93.9 \%$ in identifying suspect effort in testing. Similarly, Larrabee (2003) found that failure on any two of five embedded PVTs had a sensitivity of $87.5 \%$ and specificity of $94.4 \%$ in identifying suspect effort.

\section{Data Analyses}

Previous research has found individuals asked to simulate ADHD can successfully fake ADHD symptoms on behavior rating scales. To examine this issue once again, patients diagnosed with ADHD and making a credible effort $(n=82$ ) were compared with patients identified as making a suspect effort and not diagnosed with ADHD $(n=90)$ on the Barkley AADHDSS, BAARS-IV, BDDS-9, BFIS-SF, and BDEFS-SF rating scale continuous variables by running $t$ tests or $\chi^{2}$ tests. $\chi^{2}$ tests were run on behavior rating scale nominal variables to determine whether a patient's score was considered to be indicative of significant impairment relative to normative data.

Statistical analyses were conducted to address the issue of whether and to what degree the same two groups of patients perform similarly on several cognitive tests. $T$ tests were run comparing the performance of these two groups on 27 cognitive test measures. In clinical practice, most clinicians look to identify cognitive tests that a patient renders an impaired performance on. From a psychometric standpoint, a score in the mildly impaired range (i.e., $t$ score $<40$ ) or lower using the normative reference data is considered indicative of significant cognitive impairment. Therefore, $\chi^{2}$ tests compared the percentage of those making a suspect effort and ADHD patients who render such impaired test performances.

Frequency analyses were run to identify the specific cognitive test measures those making a suspect effort in ADHD assessment most commonly render impaired performances on in an effort to appear like they have ADHD. Most important, frequency analyses also identified what percentage of patients making a suspect effort and not diagnosed with ADHD would be diagnosed with ADHD based on their meeting several individual and combinations of diagnostic criteria.

\section{Results}

All 428 patients were given one of four diagnoses reflecting the degree to which their overall assessment results were thought to be consistent with a diagnosis of adult ADHD. Accordingly, 44 (10\%) of the patients were diagnosed as having ADHD, 58 (14\%) were identified as probably having ADHD, 136 (32\%) were identified as possibly having ADHD, and 190 (44\%) were identified as probably not having or not having ADHD. To simplify analyses, the first two groups were combined into a diagnosed with ADHD group $(n=102)$ and the last two groups were combined into a not diagnosed with ADHD group $(n=326)$. One hundred fifteen patients ( $27 \%$ of the 428 patients) made a suspect effort. Forty percent met suspect effort criteria by failing at least 2 PVTs, $29 \%$ by failing at least one PVT and the CAT-A Infrequency Scale, and 31\% by failing not only 2 or more PVTs but also the Infrequency Scale.

\section{ADHD Clinical Interview}

The results of the patient's semistructured clinical interviews conducted by the principal investigator were judged to be consistent with their having ADHD, indeterminate, or not consistent with their 
having ADHD. This judgment was made before the results of the patient's behavior rating scales, cognitive testing, and performance on PVT testing were reviewed and a final diagnosis was made. Of the 102 patients ultimately diagnosed with adult ADHD, 39\% had a clinical interview consistent with ADHD , 45\% had an indeterminate interview, and 16\% had an interview inconsistent with ADHD. Of the 115 patients who made a suspect effort, $25 \%$ provided a clinical interview that appeared to be consistent with ADHD, $46 \%$ provided an interview that was indeterminate, and $29 \%$ provided an interview that was inconsistent with ADHD.

With regards to interview questions pertaining to a family history of ADHD, only $27 \%$ of those making a suspect effort reported having a first degree relative diagnosed with ADHD and $27 \%$ reported having a non- first degree relative diagnosed with ADHD. Similarly, $22 \%$ reported having a first degree relative suspected of having ADHD and 9\% reported having a nonfirst-degree relative suspected of having ADHD. Of those patients diagnosed with ADHD during the assessment, 35\% reported having a firstdegree relative diagnosed with $A D H D, 17 \%$ reported having a nonfirst-degree relative diagnosed with $A D H D, 39 \%$ reported having a first degree relative suspected of having ADHD, and $11 \%$ reported having a nonfirst-degree relative suspected of having ADHD.

A meta-analysis of longitudinal ADHD studies found ADHD symptoms persist into adulthood in up to $65 \%$ of children with this disorder (Faraone, Biederman, \& Mick, 2006). Therefore, a patient's previous diagnosis of ADHD meaningfully increases the odds of adult ADHD. In the current study, only $11 \%$ of those making a suspect effort reported having been previously diagnosed with ADHD and provided documentation to that effect, $17 \%$ reported having been previously diagnosed but did not provide documentation, and 72\% reported no previous diagnosis of ADHD. It is interesting that the patients diagnosed with ADHD, only $14 \%$ reported having previously been diagnosed with ADHD and provided documentation, $27 \%$ reported having been previously diagnosed but provided no documentation, and $59 \%$ reported having no prior diagnosis of ADHD.

According to $D S M-5$ criteria, there should be evidence of significant cognitive problems before the age of 12 . Some clinicians have argued with good justification that the age of 16 is more appropriate (Barkley, Murphy, \& Fischer, 2008, p. 124). In any case, it is essential to determine when the patient first realized they had significant problems with ADHD symptoms. In particular, it is necessary to determine when the patient first realized they had significant problems with sustained attention because they are hallmark symptoms of ADHD. Of those patients making a suspect effort, $20 \%$ reported realizing they had significant attention problems while in elementary school, $7 \%$ in junior high school, $24 \%$ in senior high school, $28 \%$ in college, and $7 \%$ after college. Fourteen percent of those making a suspect effort either did not answer the question directly or reported being unsure of the onset. Of those patients diagnosed with ADHD, $27 \%$ reported realizing they had significant attention problems in elementary school, $13 \%$ in junior high school, $23 \%$ in senior high school, $17 \%$ in college, and $6 \%$ after college while $15 \%$ did not directly answer the question or were unsure regarding the onset of attention difficulties.

Intuitively, one would expect that most individuals who are diagnosed with adult ADHD would have had sufficiently severe ADHD related behavioral problems in their childhood or adolescence that the subject of their possibly having ADHD would have been raised by their parents or teachers (Murphy \& 
Gordon, 2006). Twenty-nine percent of the suspect effort group and 34\% of those diagnosed with ADHD reported the subject of ADHD was raised when they were growing up.

\section{ADHD Behavior Rating Scales}

The ADHD credible and suspect effort groups completed most self-report behavior rating scales similarly. Specifically, the two groups were not different with respect to the number of current and childhood inattention symptoms (counts and clinical significance) on the Barkley AADHDSS and the BAARS-IV, the BDDS-9 current symptoms, the BDEFS summary score (count and clinical significance), BDEFS symptom count score, BDEFS symptom count significant or not, and the BDEFS selfmanagement of time, self- restraint/inhibition, self-motivation, and self- regulation of emotion scores. The two groups were also not different with respect to their BFIS mean functional impairment score (count and significance). See Table 1 for specific results.

Table 1

Mean Attention-Deficit/Hyperactivity Disorder (ADHD) Self-Report Behavior Rating Scale Scores by Group

\begin{tabular}{|c|c|c|c|c|}
\hline Behavioral measure & ADHD & Suspect effort & Cohen's $d$ & Clinically significant $\chi^{2}$ \\
\hline \multicolumn{5}{|l|}{ Combined Barkley Adult Self-Report Rating Scale } \\
\hline Current DSM inattention symptoms ${ }^{\mathrm{a}}$ & $6.39(2.14)$ & $6.35(2.14)$ & .02 & .98 \\
\hline Current DSM hyperactive/impulsive symptoms ${ }^{\mathrm{a}}$ & $3.91(2.38)$ & $4.93(2.53)^{\circ}$ & -.42 & .00 \\
\hline Childhood DSM inattention symptoms ${ }^{\mathrm{a}}$ & $5.98(2.28)$ & $5.68(2.48)$ & .13 & .98 \\
\hline Childhood DSM hyperactive/impulsive symptoms ${ }^{\mathrm{a}}$ & $4.46(2.70)$ & $5.16(2.60)$ & -.26 & .02 \\
\hline Barkley best 9 symptoms ${ }^{\mathrm{a}}$ & $5.94(1.77)$ & $6.24(1.96)$ & -.16 & .12 \\
\hline \multicolumn{5}{|l|}{ Barkley Deficits in Executive Functions Scale (Short) } \\
\hline Summary score & $49.52(6.98)$ & $52.78(12.06)$ & -.33 & .35 \\
\hline Total symptoms & $9.21(2.48)$ & $10.84(4.93)$ & -.42 & .12 \\
\hline Self-management of time & $12.65(1.98)$ & $12.36(2.75)$ & .12 & \\
\hline Self-organization/planning & $8.85(2.63)$ & $10.17(3.21)$ & -.45 & \\
\hline Self-restraint/inhibition & $8.85(2.07)$ & $9.33(3.26)$ & -.18 & \\
\hline Self-motivation & $9.46(2.61)$ & $10.17(3.50)$ & -.23 & \\
\hline Self-regulation & $9.19(3.45)$ & $10.44(3.96)$ & -.34 & \\
\hline \multicolumn{5}{|l|}{ Barkley Functional Impairment Scale } \\
\hline Summary score & $4.56(1.71)$ & $4.56(2.00)$ & .00 & .47 \\
\hline
\end{tabular}

Note. $\mathrm{ADHD}=$ attention-deficit/hyperactivity disorder; $\mathrm{DSM}=$ Diagnostic and Statistical Manual. Combined Barkley Adult Self Report Rating Scale is the result of merging data from the Barkley Adult ADHD Self-Report Forms-IV (BAARS-IV) and Barkley Adult ADHD Behavior Checklist Current and Childhood Symptoms Scale.

"Denotes statistically significant group difference, $p<.05$. Clinically significant $\chi^{2}$ column reflects whether there is a difference in the number of individuals in each group identified as having clinically significant symptoms.

a Number of symptoms rated 2 or 3 .

Table 1 Mean Attention-Deficit/Hyperactivity Disorder (ADHD) Self-Report Behavior Rating Scale Scores by Group

\begin{tabular}{|l|l|l|l|l|}
\hline Behavioral measure & ADHD & Suspect effort & Cohen's $d$ & $\begin{array}{l}\text { Clinically } \\
\text { significant } \chi^{2}\end{array}$ \\
\hline Combined Barkley Adult Self-Report Rating Scale & & & & \\
\hline Current DSM inattention symptoms $^{\mathrm{a}}$ & $6.39(2.14)$ & $6.35(2.14)$ & .02 & .98 \\
\hline Current DSM hyperactive/impulsive symptoms $^{\mathrm{a}}$ & $3.91(2.38)$ & $4.93(2.53)^{*}$ & -.42 & .00 \\
\hline Childhood DSM inattention symptoms $^{\mathrm{a}}$ & $5.98(2.28)$ & $5.68(2.48)$ & .13 & .98 \\
\hline Childhood DSM hyperactive/impulsive symptoms $^{\mathrm{a}}$ & $4.46(2.70)$ & $5.16(2.60)$ & -.26 & .02 \\
\hline Barkley best 9 symptoms $^{\mathrm{a}}$ & $5.94(1.77)$ & $6.24(1.96)$ & -.16 & .12 \\
\hline Barkley Deficits in Executive Functions Scale (Short) & & & & \\
\hline Summary score & $49.52(6.98)$ & $52.78(12.06)$ & -.33 & .35 \\
\hline Total symptoms & $9.21(2.48)$ & $10.84(4.93)$ & -.42 & .12 \\
\hline Self-management of time & $12.65(1.98)$ & $12.36(2.75)$ & .12 & \\
\hline Self-organization/planning & $8.85(2.63)$ & $10.17(3.21)$ & -.45 & \\
\hline Self-restraint/inhibition & $-8.85(2.07)$ & $9.33(3.26)$ & -.18 & \\
\hline Self-motivation & $9.46(2.61)$ & $10.17(3.50)$ & -.23 & \\
\hline Self-regulation & $9.19(3.45)$ & $10.44(3.96)$ & -.34 & \\
\hline
\end{tabular}




\begin{tabular}{|c|l|l|l|l|}
\hline Barkley Functional Impairment Scale & & & & \\
\hline Summary score & $4.56(1.71)$ & $4.56(2.00)$ & .00 & .47 \\
\hline
\end{tabular}

Note. ADHD = attention-deficit/hyperactivity disorder; DSM = Diagnostic and Statistical Manual. Combined Barkley Adult Self Report Rating Scale is the result of merging data from the Barkley Adult ADHD Self-Report Forms-IV (BAARS-IV) and Barkley Adult ADHD Behavior Checklist Current and Childhood Symptoms Scale.

* Denotes statistically significant group difference, $p<.05$. Clinically significant $x^{2}$ column reflects whether there is a difference in the number of individuals in each group identified as having clinically significant symptoms.

a Number of symptoms rated 2 or 3.

The two groups did report significantly different current and childhood hyperactivity/impulsive symptoms (count and significance) on the BAARS-IV self-report measure. A higher percentage of the suspect effort group reported significant childhood ( $46 \%$ vs. $23 \%$ ) and current ( $60 \%$ vs. $36 \%$ ) problems with hyperactivity and impulsivity.

Of the 115 patients identified as making a suspect effort 104 (90\%) would be diagnosed as having adult ADHD based solely on their completing the Barkley Adult ADHD Self-Report forms (i.e., either the Barkley AADHDSS or BAARS-IV) current ADHD symptoms scales. Ninety percent of those making a suspect effort also completed the self-report childhood ADHD symptom scales in a manner consistent with ADHD. It is interesting that all 104 of these patients also completed the current symptoms scales consistent with their having this disorder. Hence, ultimately $90 \%$ of those making a suspect effort would meet the adult ADHD DSM-IV diagnostic criteria based on their completion of both the Barkley Adult ADHD Self-Report forms current and childhood ADHD symptom scales.

Eighty-three (72\%) of those making a suspect effort reported having six or more symptoms on the BBDS-9 scale and would therefore be diagnosed with ADHD on that basis. This frequency of symptom endorsement is similar to those patients who were diagnosed with ADHD: 64\% percent reported having 6 or more symptoms while $86 \%$ reported having 5 or more of these symptoms.

Approximately one half of those making a suspect effort (i.e., 48 of the 115) completed the BDEFS-SF. Of these patients, $77 \%$ reported a significant number of executive function related problems suggesting they would be diagnosed with ADHD if this was the only criteria a clinician applied. In slight contrast, $69 \%$ of those diagnosed with ADHD reported having a significant number of problems based on this criteria.

Approximately one quarter of the patients (i.e., 29 of 115) making a suspect effort were administered the BFIS-SF. Of these $29,31 \%$ reported being functionally impaired on this scale. This is not much different from the $41 \%$ of those ultimately diagnosed with ADHD who reported being functionally impaired.

Analyses of the degree of correspondence between self and informant reports on the various ADHD behavior rating scales for patients making a suspect effort and diagnosed with ADHD were also conducted. Patients in the suspect effort group completed either the Barkley AADHDSS or the BAARSIV scales in a manner consistent with their having ADHD 90\% of the time while their informants did so $75 \%$ of the time. Patients making a suspect effort and their informants completed the new BDDS-9 scale in a manner indicative of their having ADHD $72 \%$ and $50 \%$ of the time respectively. The suspect effort group completed the BDEFS-SF scale in a manner consistent with their having ADHD 77\% of the time and their informants did so $62 \%$ of the time. Finally, $57 \%$ of the suspect effort group patients and 
$27 \%$ of their informants completed the behavior rating scales in an invalid manner on the CAT-A infrequency scale.

Except for select scales, the magnitude of agreement between the behavior rating scale scores completed by suspect effort patients and their informants were not less than those between the ADHD patients and their informants (Table 2). In fact, the correlations between the suspect group and their informants are in several instances much higher than the correlations for the ADHD group and their informants for unclear reasons. This is particularly true for the BAARS-IV behavior rating scales. The fact that the correlations between patients and informants for the suspect group are higher does not support the notion that those faking ADHD exaggerate their symptoms while their informants do not.

Table 2

Correlations Between Patient and Informant Behavior Rating Scales by Group

\begin{tabular}{|c|c|c|c|}
\hline Behavioral measure & ADHD & Suspect effort & Fisher $r$-to- $z$ \\
\hline \multicolumn{4}{|l|}{ Barkley AADHDSS } \\
\hline Current DSM inattention symptoms ${ }^{\mathrm{a}}$ & .18 & $.38^{*}$ & -1.08 \\
\hline Summary score for inattention symptoms & $.39^{\circ}$ & $.33^{\circ}$ & .34 \\
\hline Current DSM hyperactive/impulsive symptoms ${ }^{\mathrm{a}}$ & $.30^{\circ}$ & $.32^{*}$ & -.11 \\
\hline Summary score for hyperactive/impulsive symptoms & $.29^{*}$ & $.26^{\circ}$ & .16 \\
\hline \multicolumn{4}{|l|}{ Barkley Adult Self Report Rating Scale-IV } \\
\hline Current DSM inattention symptoms ${ }^{\mathrm{a}}$ & $.37^{*}$ & $.66^{\circ}$ & -1.36 \\
\hline Current DSM hyperactive/impulsive symptoms ${ }^{\mathrm{a}}$ & .20 & $.74^{*}$ & $-2.51^{*}$ \\
\hline Total ADHD symptoms & .02 & $.68^{*}$ & $-2.72^{*}$ \\
\hline Current sluggish cognitive tempo score & $.15^{\circ}$ & $.40^{\circ}$ & -.92 \\
\hline Barkley best 9 symptoms ${ }^{a}$ & .21 & $.41^{*}$ & .23 \\
\hline \multicolumn{4}{|l|}{ Barkley deficits in Executive Functions Scale (Short) } \\
\hline Summary score & $.57^{*}$ & $.52^{\circ}$ & .25 \\
\hline Total Symptoms ${ }^{\mathrm{b}}$ & .34 & -.04 & 1.38 \\
\hline Self-management of time & $.19^{*}$ & $.68^{*}$ & $-2.22^{*}$ \\
\hline Self-organization/planning & $.38^{\circ}$ & $.44^{*}$ & -.25 \\
\hline Self-restraint/inhibition & $.48^{*}$ & $.40^{\circ}$ & .35 \\
\hline Self-motivation & $.56^{\circ}$ & $.50^{\circ}$ & .29 \\
\hline Self-regulation & $.66^{\circ}$ & $.49^{*}$ & .90 \\
\hline
\end{tabular}

Note. $\mathrm{ADHD}=$ attention-deficit/hyperactivity disorder; Barkley AADHDSS = Barkley Adult ADHD Behavior Checklist Current and Childhood Symptoms Scale; DSM = Diagnostic and Statistical Manual.

"Statistically significant correlation, $p<.05$.

a Number of symptoms rated 2 or 3 . ${ }^{b}$ Number of symptoms rated 3 or 4 .

Table 2 Correlations Between Patient and Informant Behavior Rating Scales by Group

\begin{tabular}{|c|c|c|c|}
\hline Behavioral measure & ADHD & Suspect effort & Fisher $r$-to-z \\
\hline \multicolumn{4}{|l|}{ Barkley AADHDSS } \\
\hline Current DSM inattention symptoms ${ }^{a}$ & .18 & $38^{*}$ & -1.08 \\
\hline Summary score for inattention symptoms & $.39 *$ & $.33^{*}$ & .34 \\
\hline Current DSM hyperactive/impulsive symptoms ${ }^{\mathrm{a}}$ & $.30^{*}$ & $.32^{*}$ & -.11 \\
\hline Summary score for hyperactive/impulsive symptoms & $.29^{*}$ & $.26^{*}$ & .16 \\
\hline \multicolumn{4}{|l|}{ Barkley Adult Self Report Rating Scale-IV } \\
\hline Current DSM inattention symptoms ${ }^{\mathrm{a}}$ & $.37 *$ & $.66^{*}$ & -1.36 \\
\hline Current DSM hyperactive/impulsive symptoms ${ }^{\mathrm{a}}$ & .20 & $.74 *$ & $-2.51^{*}$ \\
\hline Total ADHD symptoms & .02 & $.68^{*}$ & $-2.72 *$ \\
\hline Current sluggish cognitive tempo score & $.15^{*}$ & $.40^{*}$ & -.92 \\
\hline Barkley best 9 symptoms ${ }^{a}$ & .21 & $.41^{*}$ & .23 \\
\hline \multicolumn{4}{|l|}{ Barkley deficits in Executive Functions Scale (Short) } \\
\hline Summary score. & $57^{*}$ & $.52^{*}$ & .25 \\
\hline Total Symptoms ${ }^{\mathrm{b}}$ & 34 & -.04 & 1.38 \\
\hline Self-management of time & $.19 *$ & $.68 *$ & $-2.22 *$ \\
\hline
\end{tabular}




\begin{tabular}{|l|l|l|l|}
\hline Self-organization/planning & $.38^{*}$ & .44 & -.25 \\
\hline Self-restraint/inhibition & $.48^{*}$ & $.40^{*}$ & .35 \\
\hline Self-motivation & $.56^{*}$ & $.50^{*}$ & .29 \\
\hline Self-regulation & $.66^{*}$ & $.49^{*}$ & .90 \\
\hline
\end{tabular}

Note. ADHD = attention-deficit/hyperactivity disorder; Barkley AADHDSS = Barkley Adult ADHD Behav- ior Checklist Current and Childhood Symptoms Scale; DSM = Diagnostic and Statistical Manual.

* Statistically significant correlation, $p<.05$.

a Number of symptoms rated 2 or $3 .{ }^{\text {b }}$ Number of symptoms rated 3 or 4 .

Barkley has proposed that the validity of the responses on the BAARS-IV is questionable if there are large differences between the number of symptoms reported by the patient and their informant (Barkley, 2010, p. 104). Specifically, in a clinic where patients who believe they might have ADHD or have been previously diagnosed with ADHD are evaluated the following disparities should be a cause of concern: 13-15 points on the current ADHD inattention symptoms score and (b) 12-14 points on the current ADHD hyperactivity-impulsivity symptoms score. Discrepancies of this magnitude were rarely observed in the current study. Only 3 of the 115 individuals making a suspect effort had such a large discrepancy. Only two additional patients were even close (i.e., within 3 points) to having a difference of this magnitude between the symptom scores.

\section{Cognitive Testing}

The mean cognitive test performances of patients diagnosed with ADHD performing credibly $(n=82)$ were compared with patients identified as making a suspect effort and not diagnosed with ADHD ( $n=$ 90; Table 3). The ADHD credible group's performance was not significantly different from the performance of this suspect effort group on four executive function test variables (Design Fluency switching vs. combined filled and empty dot and percent design accuracy, Color Word Interference inhibition vs. color naming, and Tower Test move accuracy) and two attention test variables (Sentence Repetition and NAB Number and Letters Test Part A speed). 
Table 3

Mean Cognitive Test $t$ Scores and Percentage Impaired by Group

\begin{tabular}{|c|c|c|c|c|c|}
\hline \multirow[b]{2}{*}{ Cognitive measure } & \multicolumn{2}{|c|}{$\mathrm{ADHD}$} & \multicolumn{2}{|c|}{ Suspect effort } & \multirow[b]{2}{*}{ Cohen's $d$} \\
\hline & $M(S D)$ & \% Impaired & $M(S D)$ & $\%$ Impaired & \\
\hline WAIS-IV Estimated FSIQ & $63.01(8.28)$ & & $54.28(9.99)^{\circ}$ & & .95 \\
\hline WAIS-IV Letter Number Sequencing & $54.09(9.37)$ & 2 & $46.30(9.79)^{\circ}$ & $16^{* *}$ & .81 \\
\hline WAIS-IV Digit Span Forward & $46.29(9.46)$ & & $41.75(9.22)^{*}$ & & .49 \\
\hline WAIS-IV Digit Span Backward & $48.21(9.84)$ & 28 & $43.20(9.14)^{\circ}$ & 12 & .53 \\
\hline CVLT Learning Trial $1-5$ & $50.06(10.87)$ & 11 & $42.03(9.76)^{\circ}$ & $30^{* *}$ & .78 \\
\hline CVLT Semantic Clustering & $54.30(13.80)$ & & $47.92(8.11)^{\circ}$ & & .56 \\
\hline CVLT Short Delay Free Recall & $51.15(10.81)$ & & $40.94(11.31)^{\circ}$ & & .92 \\
\hline CVLT Long Delay Free Recall & $47.69(10.34)$ & 19 & $39.53(12.68)^{\circ}$ & $33^{* *}$ & .71 \\
\hline Rey Osterreith Copy Organization Score & $40.09(10.12)$ & & $33.85(11.78)^{\circ}$ & & .57 \\
\hline DKEFS DF Switching/Combined Filled and Empty Dots & $49.34(9.45)$ & & $49.08(9.69)$ & & .03 \\
\hline DKEFS DF Percent Design Accuracy & $48.59(8.02)$ & 13 & $46.22(11.12)$ & 20 & .24 \\
\hline DKEFS DF Combined Empty/Filled Dots & $56.38(8.39)$ & 1 & $51.72(9.96)^{\circ}$ & $7^{* *}$ & .51 \\
\hline DKEFS Letter Fluency total correct & $55.64(10.92)$ & & $50.56(10.09)^{\circ}$ & & .48 \\
\hline DKEFS CW Interference Inhibition vs. Color Naming & $52.51(9.32)$ & 8 & $50.65(9.42)$ & 11 & .20 \\
\hline DKEFS CW Interference Combined Naming/Reading & $51.27(7.14)$ & 6 & $44.85(11.51)^{*}$ & $18^{* *}$ & .67 \\
\hline DKEFS Tower Total Achievement & $52.51(8.27)$ & 5 & $50.01(8.27)^{\circ}$ & 10 & .30 \\
\hline DKEFS Tower Move Accuracy & $47.58(8.88)$ & 13 & $49.00(7.59)$ & 8 & -.17 \\
\hline Sentence repetition & $47.73(13.53)$ & & $44.56(12.43)$ & & .24 \\
\hline PASAT-100 Total Correct & $44.94(9.89)$ & 33 & $41.37(8.99)^{\circ}$ & 44 & .38 \\
\hline TOVA Commission Errors & $44.73(13.10)$ & 30 & $38.45(16.97)^{\circ}$ & 45 & .41 \\
\hline TOVA Omission Errors & $31.03(17.04)$ & 56 & $19.17(15.51)^{\circ}$ & $81^{* *}$ & .73 \\
\hline TOVA Reaction Time Variability & $28.76(12.75)$ & 83 & $17.90(12.73)^{\circ}$ & 87 & .85 \\
\hline NAB Number and Letter Part A Speed & $48.51(14.06)$ & 22 & $47.94(14.02)$ & 26 & .04 \\
\hline NAB Number and Letter Part A Errors & $38.71(12.33)$ & 30 & $32.30(10.77)^{\circ}$ & $68^{* *}$ & .55 \\
\hline Sentence span & $40.44(11.26)$ & 60 & $32.04(10.88)^{\circ}$ & $83^{* *}$ & .76 \\
\hline Short Category Test total correct & $53.26(13.99)$ & $15^{\mathrm{a}}$ & $45.80(9.11)^{\circ}$ & $29^{1}$ & .63 \\
\hline WMS-IV Spatial Addition & $52.00(10.86)$ & & $44.24(10.48)^{\circ}$ & & .73 \\
\hline
\end{tabular}

Note. $\mathrm{ADHD}=$ attention-deficit/hyperactivity disorder; WAIS-IV $=$ Wechsler Adult Intelligence Scale-Fourth Edition; CVLT $=$ California Verbal Learning Test; DKEFS = Delis-Kaplan Executive Function System; DF = Design fluency; PASAT-100 = Paced Auditory Serial Addition Test-100; TOVA $=$ Test of Variables of Attention; NAB $=$ Neuropsychological Assessment Battery; WMS-IV $=$ Wechsler Memory Scale-IV.

"Statistically significant group mean difference, $p<.05$. " Statistically significant difference in the percentage of individuals scoring in the impaired range based on $\chi^{2}$.

a Based on errors.

Table 3 Mean Cognitive Test t Scores and Percentage Impaired by Group

\begin{tabular}{|l|l|l|l|l|l|}
\hline & ADHD & & Suspect effort & & \\
\hline Cognitive measure & M (SD) & \% Impaired & M (SD) & \% Impaired & Cohen's d \\
\hline WAIS-IV Estimated FSIQ & $63.01(8.28)$ & & $54.28(9.99)^{*}$ & & .95 \\
\hline WAIS-IV Letter Number Sequencing & $54.09(9.37)$ & 2 & $46.30(9.79)^{*}$ & $16^{* *}$ & .81 \\
\hline WAIS-IV Digit Span Forward & $46.29(9.46)$ & & $41.75(9.22)^{*}$ & & .49 \\
\hline WAIS-IV Digit Span Backward & $48.21(9.84)$ & 28 & $43.20(9.14)^{*}$ & 12 & .53 \\
\hline CVLT Learning Trial 1-5 & $50.06(10.87)$ & 11 & $42.03(9.76)^{*}$ & $30^{* *}$ & .78 \\
\hline CVLT Semantic Clustering & $54.30(13.80)$ & & $47.92(8.11)^{*}$ & & .56 \\
\hline CVLT Short Delay Free Recall & $51.15(10.81)$ & & $40.94(11.31)^{*}$ & & .92 \\
\hline CVLT Long Delay Free Recall & $47.69(10.34)$ & 19 & $39.53(12.68)^{*}$ & $33^{* *}$ & .71 \\
\hline Rey Osterreith Copy Organization Score & $40.09(10.12)$ & & $33.85(11.78)^{*}$ & & .57 \\
\hline $\begin{array}{l}\text { DKEFS DF Switching/Combined Filled and } \\
\text { Empty Dots }\end{array}$ & $49.34(9.45)$ & & $49.08(9.69)$ & & .03 \\
\hline DKEFS DF Percent Design Accuracy & $48.59(8.02)$ & 13 & $46.22(11.12)$ & 20 & .24 \\
\hline DKEFS DF Combined Empty/Filled Dots & $56.38(8.39)$ & 1 & $51.72(9.96)^{*}$ & $7^{* *}$ & .51 \\
\hline DKEFS Letter Fluency total correct & $55.64(10.92)$ & & $50.56(10.09)^{*}$ & & .48 \\
\hline $\begin{array}{l}\text { DKEFS CW Interference Inhibition vs. Color } \\
\text { Naming }\end{array}$ & $52.51(9.32)$ & 8 & $50.65(9.42)$ & 11 & .20 \\
\hline $\begin{array}{l}\text { DKEFS CW Interference Combined } \\
\text { Naming/Reading }\end{array}$ & $51.27(7.14)$ & 6 & $44.85(11.51)^{*}$ & $18^{* *}$ & .67 \\
\hline DKEFS Tower Total Achievement & $52.51(8.27)$ & 5 & $50.01(8.27)^{*}$ & 10 & .30 \\
\hline DKEFS Tower Move Accuracy & $47.58(8.88)$ & 13 & $49.00(7.59)$ & 8 & -.17 \\
\hline
\end{tabular}




\begin{tabular}{|l|l|l|l|l|l|}
\hline Sentence repetition & $47.73(13.53)$ & & $44.56(12.43)$ & & .24 \\
\hline PASAT-100 Total Correct & $44.94(9.89)$ & 33 & $41.37(8.99)^{*}$ & 44 & .38 \\
\hline TOVA Commission Errors & $44.73(13.10)$ & 30 & $38.45(16.97)^{*}$ & 45 & .41 \\
\hline TOVA Omission Errors & $31.03(17.04)$ & 56 & $19.17(15.51)^{*}$ & $81^{* *}$ & .73 \\
\hline TOVA Reaction Time Variability & $28.76(12.75)$ & 83 & $17.90(12.73)^{*}$ & 87 & .85 \\
\hline NAB Number and Letter Part A Speed & $48.51(14.06)$ & 22 & $47.94(14.02)$ & 26 & .04 \\
\hline NAB Number and Letter Part A Errors & $38.71(12.33)$ & 30 & $32.30(10.77)^{*}$ & $68^{* *}$ & .55 \\
\hline Sentence span & $40.44(11.26)$ & 60 & $32.04(10.88)^{*}$ & $83^{* *}$ & .76 \\
\hline Short Category Test total correct & $53.26(13.99)$ & $15^{\text {a }}$ & $45.80(9.11)^{*}$ & $29^{1}$ & .63 \\
\hline WMS-IV Spatial Addition & $52.00(10.86)$ & & $44.24(10.48)^{*}$ & & .73 \\
\hline
\end{tabular}

Note. $\quad$ ADHD $=$ attention-deficit/hyperactivity disorder; WAIS-IV = Wechsler Adult Intelligence Scale-Fourth Edition; CVLT = California Verbal Learning Test DKEFS = Delis-Kaplan Executive Function System; DF = Design fluency; PASAT-100 = Paced Auditory Serial Addition Test-100; TOVA $=$ Test of Variables of Attention; NAB $=$ Neuropsychological Assessment Battery; WMS-IV = Wechsler Memory Scale-IV.

* Statistically significant group mean difference, $p<.05 .{ }^{* *}$ Statistically significant difference in the percentage of individuals scoring in the impaired range based on $\mathrm{x}^{2}$.

a Based on errors.

The suspect effort group performed significantly more poorly than the ADHD credible group on numerous cognitive tests, that is, two cognitive processing speed, one estimated FSIQ, five working memory, four memory, five executive function, and six attention test variables.

It is noteworthy the suspect effort group mean $\mathrm{t}$ scores were in the average range for the majority of cognitive test variables. The exceptions were CVLT-II long delay free recall ( $t$ score $=39$ ), Rey Osterreith copy $(t$ score $=34)$, NAB Number and Letters part A errors $(t$ score $=32)$, Salthouse Listening Span score $(t$ score $=32)$, and TOVA omission errors ( $t$ score $=19)$, commission errors $(t$ score $=38)$, and reaction time $(\mathrm{RT})$ variability scores $(t$ score $=18)$. In addition, the patients diagnosed with ADHD did not do better (in a statistically significant manner) than the suspect effort patients on any test variables.

In summary, on a group basis, individuals exaggerating or feigning ADHD symptoms exhibit very little difficulty on most cognitive tests, perform similarly to patients diagnosed with ADHD on most tests, and have more difficulty than those diagnosed with ADHD on some tests. Therefore, on a group basis, one may conclude that individuals making a suspect effort can and do perform on cognitive testing in a manner that could lead to their being diagnosed with adult ADHD.

While comparing patients' performances on a group basis is informative, it is also important to consider the percentage of patients diagnosed with ADHD and those making a suspect effort who render impaired performances (i.e., have $t$ scores $<40$ ) on various cognitive tests. Those percentages are presented in Table 3 . It is important that $92 \%$ of those making a suspect effort rendered an impaired performance on at least one cognitive test measure, not taking into consideration their performance on the TOVA on which $87 \%$ gave an impaired performance.

The results in Table 3 reveal two important facts. Consistent with the findings of many other studies, a patient's rendering an impaired performance (i.e., $\mathrm{t}$ score $<40$ based on general population normative data) on any single cognitive test will not be a good predictor of adult ADHD diagnosis. At least in this study, only two tests have reasonably good sensitivity based on a significant number of ADHD patients rendering impaired performances on them: the TOVA test (omission errors and RT variability scores) and the NAB Number and Letters Part A errors. However, neither of these test measures has 
acceptable specificity in differentiating patients diagnosed with ADHD from those making a suspect effort. In fact, individuals exaggerating or feigning ADHD symptoms are as likely, or even more likely, than individuals diagnosed with ADHD to render an impaired test performance. These findings suggest once again individuals exaggerating or faking ADHD symptoms can present in a manner on cognitive testing that would be indistinguishable from those diagnosed with adult ADHD.

\section{Discussion}

The results of this study are consistent with an emerging body of literature that indicates individuals feigning or exaggerating symptoms associated with ADHD complete self-report measures and cognitive tests in a manner that is nearly indistinguishable from genuine ADHD patients. This study builds upon prior research by investigating potential differences in what information is presented during a clinical interview, discrepancies between self- and observer report, and performances on a broader range of self-report and cognitive measures.

The present results indicate clinical patients making a suspect effort do not differ from those patients diagnosed with ADHD in responding to several important clinical interview questions to a degree that their answers to these questions would be helpful in differentiating the two groups. Specifically, the two groups generally answer questions concerning the onset and chronicity of ADHD symptoms in a similar manner. Slightly more (i.e., 59\%) of the suspect effort group than those diagnosed with ADHD (46\%) report first realizing they had significant problems with attention after junior high school which is inconsistent with current diagnostic criteria. Patients making a suspect effort (i.e., 29\%) and diagnosed with ADHD (i.e., 34\%) report the subject of their possibly having ADHD was raised by their parents or teachers as they were growing up.

The two groups also generally answer questions about factors that would increase the likelihood of their having ADHD in a similar manner. Specifically, nearly $50 \%$ of each group report having a relative diagnosed with ADHD. A smaller percentage of suspect effort patients (i.e., 28\%) reported having been previously diagnosed with ADHD (with and without providing documentation) than the $41 \%$ of those diagnosed with ADHD. This larger discrepancy may have been due a policy of the primary referral source for the patients in this study (a large university). They would not treat students previously diagnosed with ADHD unless they had been given this diagnosis on the basis of a good evaluation completed within 3 years. If they did not have documentation of such an evaluation, they were referred to our clinic for adult ADHD assessment.

Based solely on information obtained during a clinical interview, $25 \%$ of patients making a suspect effort had a background that suggests the presence ADHD. An additional 46\% provided information that was indeterminate with regard to their having this disorder. Thus, only $29 \%$ provided an interview that was not consistent with their having ADHD and, hence, would significantly reduce the likelihood of their being diagnosed with ADHD.

As prior simulator and clinical patient research has found, patients feigning or exaggerating ADHD symptoms can complete ADHD behavior rating scales in a manner consistent with their having adult ADHD. Specifically, these suspect effort patients did not differ from patients diagnosed with ADHD with respect to most of the Barkley AADHDSS (2006) and BAARS-IV (2010) scales. For example, the two groups did not differ on the number of current and childhood inattention symptoms they endorsed 
with respect to both the total symptom count and whether that count was indicative of their having ADHD or not. The two groups did differ significantly from a statistical standpoint with respect to their self-report of the number of current and childhood hyperactive/impulsive symptoms (i.e., total count and whether this count was indicative of their having ADHD) they have. A higher percentage of the suspect effort group reported having significant problems with childhood and current hyperactivity/impulsivity symptoms. This suggests individuals distorting their presentation do so in a manner that reflects severe ADHD as opposed to reporting mild symptoms that still may result in clinically significant impairment.

Patients exaggerating or faking ADHD symptoms also completed the BDEFS in a manner that does not differentiate them from patients diagnosed with ADHD. Specifically, the two groups are indistinguishable on all 8 BDEFS-SF symptom measures, including the two indices considered to be most important in making the diagnosis of ADHD: whether the summary score or total symptom count was indicative of their having ADHD. In fact, those making a suspect effort endorse having at least as many-if not more-difficulties with executive function ability related behaviors than those diagnosed with ADHD. This is an important finding because the BDEFS, unlike the BAARS-IV ADHD behavior rating scales, does not contain just the specific DSM ADHD behavioral symptoms and, hence, could have been more difficult for those feigning ADHD to complete in a manner consistent with that diagnosis.

Patients making a suspect effort completed a measure assessing the degree to which they are functionally impaired in several important domains of daily living in a manner indistinguishable from patients diagnosed with ADHD. That is, the two groups reported having similar levels of overall impairment with respect to their function in the workplace, in personal relationships with friends and family, in household management, in educational activities, and in their ability to care for themselves on the Barkley Functional Impairment Scale.

Barkley (2010) has noted that certain large discrepancies between self and informant inattention and hyperactivity total symptom scores on the BAARS-IV are so rare in the normative sample that they should raise concerns about the honesty with which the BAARS-IV was completed. However, these discrepancy scores are likely ineffective in detecting distorted responding as these extreme discrepancies were seen only in 3 of the 115 patients in the suspect effort group.

Consistent with prior research, patients making a suspect effort also perform on an even more broad range of cognitive tests in a manner indistinguishable from patients diagnosed with ADHD on a group basis. This includes tests that research and theory would suggest ADHD patients might have difficulty on. This also includes tests that are more challenging and, hence, potentially more effective in identifying individuals with ADHD. The test performances of the suspect effort group were indistinguishable from ADHD patients or slightly worse on tests of verbal memory encoding and retrieval, verbal and spatial working memory, sustained attention over shorter and longer time frames, and cognitive processing speed. The two groups were also indistinguishable on tests of several executive function abilities, that is, response inhibition, creative initiative/productivity for both verbal and figural material, simple planning/organization, and abstract and conceptual reasoning.

Prior research (Marshall et al., 2010) has found that patients making a suspect effort render impaired performances on tests that look like they involve sustained attention in particular, that is, the TOVA 
and PVT tests like the $\mathrm{b}$ test and the Word Memory Test. In the current study, $87 \%$ of those faking ADHD rendered an impaired performance on the TOVA and would be diagnosed with ADHD if these results were taken at face value. Several studies have found that college students can also successfully simulate ADHD on two other continuous performance tests of sustained attention-the Integrated Visual and Auditory Continuous Performance Test (IVA CPT) (Quinn, 2003) and the Conners Continuous Performance Test-II (CPT-II; Booksh et al., 2010; Sollman et al., 2010; Suhr et al., 2011). Therefore, it would not be at all surprising if a similar majority of patients exaggerating or feigning ADHD symptoms would be able to perform on those two continuous performance tests in a manner indicative of their having ADHD. However, unlike the IVA CPT and Conners CPT-II, the TOVA has measures with cutoff scores that identify those making an inadequate effort (Greenberg et al., 1996; Marshall, et al., 2010) and decrease the likelihood of a clinician being misled by their performance on this test. In fact, only $21 \%$ of those faking ADHD who gave an impaired performance on the TOVA in the current study were not identified as making an inadequate effort by the TOVA effort measures.

Clinicians differ with respect to the methods they use to diagnose adult ADHD. As a consequence, it is important to examine how many young adult patients feigning or exaggerating ADHD symptoms would potentially be incorrectly diagnosed with this disorder depending upon what assessment methods are employed. Though this approach is debatable, most clinicians would prefer to over diagnose than under diagnose ADHD given the fact that the negative consequences of not treating ADHD outweigh the negative consequences of treating a patient who does not have this disorder. Therefore, it would be reasonable to assume patients who give clinical interviews consistent or indeterminate with their having ADHD would most often be diagnosed with ADHD on the basis of the clinical interview alone. Based on this assumption, $71 \%$ of those 115 patients making a suspect effort would be diagnosed with ADHD on the basis of the clinical interview alone. The next step in the diagnostic process for many clinicians would be to examine the patient's ADHD behavior rating scales. Based on the results of the Barkley AADHDSS and BAARS-IV self-report current behavior rating scales being consistent with ADHD, 65\% of the 115 suspect effort group patients would be diagnosed with this disorder based on their clinical interview and ADHD behavior rating scales. This is an important finding since the great majority of adult ADHD evaluations include only a clinical interview and ADHD behavior rating scales.

A much smaller number of clinicians also incorporate cognitive testing into the evaluation process (though many only administer a continuous performance test). In the current study, $87 \%$ of patients making a suspect effort gave an impaired performance on the TOVA. Let us assume that the percentage of patients successfully feigning ADHD on the TOVA (not taking into account the TOVA effort measures) is very similar to the percentage that would do so successfully on the IVA-CPT and Conners CPT-II. Based on this not unreasonable assumption, $57 \%$ of the suspect effort group would still be diagnosed with ADHD on the basis of the clinical interview, the Barkley Adult ADHD Self-Report behavior rating scales (current symptoms), and a continuous performance test.

As an alternative, a clinician might administer a short battery of tests thought to be sensitive to ADHD similar to the current test battery. Because research suggests that many patients with ADHD do not give impaired performances on such tests, it might be reasonable for a clinician to consider their rendering even one impaired test performance as supporting an ADHD diagnosis. Based on this 
assumption, $62 \%$ of the suspect effort group would still be diagnosed with ADHD on the basis of the clinical interview, behavior rating scales, and rendering an impaired performance on one test other than the TOVA.

Because executive function behavior rating scales are thought to predict adult ADHD diagnosis, some clinicians might choose to use the BDEFS rather than any cognitive testing in their ADHD assessments. Unfortunately, $54 \%$ of the 115 patients making a suspect effort would still be diagnosed with ADHD based on the result of the clinical interview, the Barkley Adult ADHD Self Report scales (current symptoms), and the BDEFS combined.

To summarize, 115 patients were identified as feigning or exaggerating ADHD deficits in this study. Of these 115 patients, $71 \%$ of them would be diagnosed with ADHD on the basis of a clinical interview alone and $65 \%$ would be diagnosed on the basis of a clinical interview and the ADHD behavior rating scales together. $54 \%$ of these patients would get this diagnosis based on the combination of the results of a clinical interview and the Barkley ADHD behavior rating scales as well as their exhibiting impairment on at least one cognitive test other than the TOVA. Finally, if a continuous performance test that contained no effort measures was used, $62 \%$ of those exaggerating or feigning ADHD symptoms would be diagnosed with this disorder based on the clinical interview and the Barkley ADHD behavior rating scales, as well as their giving an impaired performance (that was taken at face value) on a continuous performance test.

This study has several limitations that should be recognized. A key limitation is that all diagnoses of ADHD were made by one clinician (PM). To further explore this limitation, the reliability of the clinical interview was established by reviewing only background information provided in 57 integrated neuropsychological clinical reports. Overall rater agreement was $72 \%(\kappa=.57$, ICC $(2,1)=.64)$. While this agreement is only considered fair to good (Landis \& Koch, 1977), it is important to interpret this reliability coefficient in the context of the clinic, which typically receives referrals from predominantly psychiatrists that are unable to determine whether an individual does or does not have ADHD. To some degree, this limitation is irrelevant with the respect to the identification of those making a suspect effort or interpretation of test scores. The former diagnosis was made objectively and strictly on the basis of patients' performances on PVTs, their completion of the CAT-A Infrequency Scale, and their meeting the Slick criteria for malingering. It is important to acknowledge that some percentage of the suspect effort group may in fact genuinely have ADHD, though it is unknown based on their extreme response distortion and suboptimal effort. While each clinician will deal differently with this possibility in a clinical context, in a research context it is ideal to exclude those participants in order to present a clear picture of behavioral and cognitive difficulties associated with ADHD. This is an important detail that is often overlooked by researchers. The failure to exclude individuals with less than sufficient effort confounds attempts to evaluate the effectiveness of neuropsychological measures in differentiating patient groups.

It is also important to note that the clinical interview was conducted only with the patient in this study. Some clinicians also do informant interviews that could provide information strongly suggesting a patient does not have ADHD or is feigning ADHD. Doing so would allow one to more comprehensively evaluate the congruency of patient and observer report. Simply put, it is unclear whether informants or patients completed observational symptom scales. It is possible some patients completed their 
informant scales. In addition, it is unclear how many of these patients were seeking medication treatment alone, accommodations alone, or both. No attempt was made to make a diagnosis of malingering, factitious disorder, or somatoform disorder that could explain a patient's suspect effort. Furthermore, suspect effort could also be construed as a cry for help or an effort to ensure that the patient with bona fide ADHD is diagnosed with the disorder.

It is also possible that patients who were prescribed ADHD medication and using alcohol, other drugs, and caffeine did not did not comply with the request to refrain from using these substances for varying time periods prior to the assessment session. The majority (i.e., 79\%) of the study participants were between the ages of 17-30 and most were undergraduate and graduate students. These results may not generalize to a wider range of adults referred for ADHD assessment.

In conclusion, the results of this study indicate a significant number of young adults-that is, $27 \%$ of this sample-exaggerate or feign ADHD symptoms when presenting for adult ADHD assessment. Furthermore, the majority of patients making a suspect effort in adult ADHD assessment (i.e., between 56 and 70\% depending upon the assessment methods used) would be incorrectly diagnosed with this disorder. The difficulty and importance of identifying distorted presentations in clinical evaluations in general is well understood. This has led the National Academy of Neuropsychology to state as a matter of policy the following: "Data from PVTs should generally be given substantially greater weight than subjective indicators of suboptimal effort. Subjective indicators, such as examinee statements and examiner observations, should be afforded less weight because of the lack of scientific evidence supporting their validity" (Bush et al., 2005, p. 424). As a consequence, it is essential that adult ADHD assessments include validity scales in adult ADHD behavior rating scales as well as PVT tests to identify exaggeration or complete feigning of ADHD cognitive deficits. Finally, it is also necessary to include such measures to be able to exclude subjects making such suspect effort in research attempting to clarify the relative effectiveness of cognitive tests and other behavioral measures in diagnosing adult ADHD.

\section{References}

Babikian, T., Boone, K. B., Lu, P., \& Arnold, G. (2006). Sensitivity and specificity of various digit span scores in the detection of suspect effort. The Clinical Neuropsychologist, 20, 145-159. 10.1080/13854040590947362

Barkley, R. (2011a). Barkley Adult ADHD Self-Report Forms-IV (BAARS-IV). New York, NY: Guilford Press. Barkley, R. (2011b). Barkley Deficits in Executive Functioning Scale (BDEFS). New York, NY: Guilford Press. Barkley, R. (2011c). Barkley Functional Impairment Scale (BFIS). New York, NY: Guilford Press.

Barkley, R. A., Knouse, L. E., \& Murphy, K. R. (2011). Correspondence and disparity in the self- and other ratings of current and childhood ADHD symptoms and impairment in adults with ADHD. Psychological Assessment, 23, 437-446. 10.1037/a0022172

Barkley, R., \& Murphy, K. (2006). Attention-deficit hyperactivity disorder: A clinical workbook (3rd ed.). New York, NY: Guilford Press.

Barkley, R., \& Murphy, K. (2011). The nature of executive function (EF) deficits in daily life activities in adults with ADHD and their relationship to performance on EF tests. Journal of Psychopathology and Behavior Assessment, 33, 137-158.

Barkley, R., Murphy, K., \& Fischer, M. (2008). ADHD in adults: What the science says. New York, NY: Guilford Press. 
Booksh, R. L., Pella, R. D., Singh, A. N., \& Gouvier, W. D. (2010). Ability of college students to simulate ADHD on objective measures of attention. Journal of Attention Disorders, 13, 325-338.

$10.1177 / 1087054708329927$

Boone, K. B. (2009). The need for continuous and comprehensive sampling of effort/response bias during neuropsychological examinations. The Clinical Neuropsychologist, 23, 729-741.

$10.1080 / 13854040802427803$

Boone, K., Lu, P., \& Herzberg, D. (2002a). The b Test. Los Angeles, CA: Western Psychological Services.

Boone, K., Lu, P., \& Herzberg, D. (2002b). The Dot Counting Test. Los Angeles, CA: Western Psychological Services.

Bracken, B., \& Boatwright, B. (2005). CAT-A: Clinical Assessment of Attention Deficit-Adult professional manual. Lutz, FL: Psychological Assessment Resources.

Braun, D., Dulit, R., Adler, D., Berlant, J., Dixon, L., Fornari, V., \& Richter, D. (2004). Attention-deficit hyperactivity disorder in adults: Clinical information for primary care physicians. Primary Psychiatry, 11, 56-65.

Bush, S. S., Ruff, R. M., Tröster, A. I., Barth, J. T., Koffler, S. P., Pliskin, N. H., . . Silver, C. H. (2005). Symptom validity assessment: Practice issues and medical necessity NAN policy \& planning committee. Archives of Clinical Neuropsychology, 20, 419-426. 10.1016/j.acn.2005.02.002

Conners, K., Erhardt, D., \& Sparrow, E. (1999). Conners Adult ADHD Rating Scales Technical Manual. Tonawanda, New York: Multi-Health Systems, Inc.

Dean, A., Victor, T., Boone, K., \& Arnold, G. (2008). The relationship of IQ to effort test performance. The Clinical Neuropsychologist, 22, 705-722.

Delis, D., Kaplan, E., \& Kramer, J. H. (2001). Delis-Kaplan executive function system. San Antonio, TX: The Psychological Corporation.

Delis, D., Kramer, J. H., Kaplan, E., \& Ober, B. A. (2000). California Verbal learning test (2nd ed.). San Antonio, TX: The Psychological Corporation, Harcourt Assessment Company.

Diehr, M. C., Cherner, M., Wolfson, T. J., Miller, S. W., Grant, I., Heaton, R. K., \& H. I. V. Neurobehavioral Research Center., \& the HIV Neurobehavioral Research Center Group. (2003). The 50 and 100-item short forms of the Paced Auditory Serial Addition Task (PASAT): Demographically corrected norms and comparisons with the full PASAT in normal and clinical samples. Journal of Clinical and Experimental Neuropsychology, 25, 571-585. 10.1076/jcen.25.4.571.13876

DuPaul, A., Power, T., Anastopoulos, A., \& Reid, R. (1998). ADHD rating scale IV: Checklists, norms, \& clinical interpretation. New York: Guilford Press.

Faraone, S. V., Biederman, J., \& Mick, E. (2006). The age-dependent decline of attention deficit hyperactivity disorder: A meta-analysis of follow-up studies. Psychological Medicine, 36, 159-165. 10.1017/S003329170500471X

Faust, D., Guilmette, T. J., Hart, K., Arkes, H. R., Fishburne, F. J., \& Davey, L. (1988). Neuropsychologists' training, experience, and judgment accuracy. Archives of Clinical Neuropsychology, 3, 145-163. 10.1093/arclin/3.2.145

Faust, D., Hart, K., Guilmette, T., \& Arkes, H. (1988). Neuropsychologists capacity to detect adolescent malingerers. Professional Psychology: Research and Practice, 19, 508-515. 10.1037/0735-7028.19.5.508

Fisher, A., \& Watkins, M. (2008). ADHD rating scales-susceptibility to faking in a college student sample. Journal of Postsecondary Education and Disability, 20, 81-92.

Frazier, T. W., Demaree, H. A., \& Youngstrom, E. A. (2004). Meta-analysis of intellectual and neuropsychological test performance in attention-deficit/hyperactivity disorder. Neuropsychology, 18, 543-555. 10.1037/0894-4105.18.3.543

Freitag, C., \& Retz, W. (2010). Family and twin studies in attention-deficit/hyperactivity disorder. In W.Retz \& R.Klein (Eds.), Attention-deficit/hyperactivity disorder (ADHD) in adults Key issues in mental health (Vol. 176, pp. 38-57). Basel, Switzerland: Karger Press. 10.1159/000258448

Green, P. (2003). The Word Memory test. Seattle, WA: Green's Publishing Inc. 
Greenberg, L., Kindschi, C., Dupuy, T., \& Corman, C. (1996). Test of variables of attention. Los Alamitos, CA: Universal Attention Disorders.

Greenfield, B., Ochs, E., \& Hechtman, L. (2002). Diagnosing attention deficit-hyperactivity disorder in adults: Challenges and controversies. Drug Benefit Trends, 14, 27-33.

Haavik, J., Halmøy, A., Lundervold, A. J., \& Fasmer, O. B. (2010). Clinical assessment and diagnosis of adults with attention-deficit/hyperactivity disorder. Expert Review of Neurotherapeutics, 10, 1569-1580. 10.1586/ern.10.149

Harp, J., Jasinski, L., Shandera-Ochsner, A., Mason, L., \& Berry, D. (2011). Detection of malingered ADHD using the MMPI-2 RF. Psychological Injury and Law, 4, 32-43.

Harrison, A., \& Edwards, M. (2010). Symptom exaggeration in post-secondary students: Preliminary base rates in a Canadian sample. Applied Neuropsychology, 17, 135-143.

Harrison, A. G., Edwards, M. J., \& Parker, K. C. (2007). Identifying students faking ADHD: Preliminary findings and strategies for detection. Archives of Clinical Neuropsychology, 22, 577-588. 10.1016/j.acn.2007.03.008

Hervey, A. S., Epstein, J. N., \& Curry, J. F. (2004). Neuropsychology of adults with attention-deficit/hyperactivity disorder: A meta-analytic review. Neuropsychology, 18, 485-503. 10.1037/0894-4105.18.3.485

In de Braek, D., Dijkstra, J. B., \& Jolles, J. (2011). Cognitive complaints and neuropsychological functioning in adults with and without attention-deficit hyperactivity disorder referred for multidisciplinary assessment. Applied Neuropsychology, 18, 127-135. 10.1080/09084282.2011.570614

Jachimowicz, G., \& Geiselman, R. (2004). Comparison of ease of falsification of attention-deficit/hyperactivity disorder diagnosis using standard behavior rating scales. Cognitive Science Online, 2, 6-20.

Jasinski, L. J., Harp, J. P., Berry, D. T., Shandera-Ochsner, A. L., Mason, L. H., \& Ranseen, J. D. (2011). Using symptom validity tests to detect malingered ADHD in college students. The Clinical Neuropsychologist, 25, 1415-1428. 10.1080/13854046.2011.630024

Kessler, R. C., Green, J. G., Adler, L. A., Barkley, R. A., Chatterji, S., Faraone, S. V., . . Van Brunt, D. L. (2010). Structure and diagnosis of adult attention-deficit/hyperactivity disorder: Analysis of expanded symptom criteria from the Adult ADHD Clinical Diagnostic Scale. Archives of General Psychiatry, 67, 1168-1178. 10.1001/archgenpsychiatry.2010.146

Landis, J. R., \& Koch, G. G. (1977). The measurement of observer agreement for categorical data. Biometrics, 33, 159-174. 10.2307/2529310

Larrabee, G. (2000). Forensic neuropsychological assessment. In R.Vanderploeg (Ed.), Clinician's Guide to Neuropsychological Assessment (2nd ed., pp. 301-335). Mahwah, NJ: Erlbaum.

Larrabee, G. J. (2003). Detection of malingering using atypical performance patterns on standard neuropsychological tests. The Clinical Neuropsychologist, 17, 410-425. 10.1076/clin.17.3.410.18089

Marshall, P., Schroeder, R., O’Brien, J., Fischer, R., Ries, A., Blesi, B., \& Barker, J. (2010). Effectiveness of symptom validity measures in identifying cognitive and behavioral symptom exaggeration in adult attention deficit hyperactivity disorder. The Clinical Neuropsychologist, 24, 1204-1237. 10.1080/13854046.2010.514290

McGough, J. J., \& Barkley, R. A. (2004). Diagnostic controversies in adult attention deficit disorder. American Journal of Psychiatry, 161, 1948-1956.

Meyers, J., \& Meyers, K. (1995). Rey Complex Figure Test and recognition trial. Odessa, FL: Psychological Assessment Resources.

Murphy, K., \& Barkley, R. (1996). Prevalence of DSM-IV ADHD symptoms in adult licensed drivers. Journal of Attention Disorders, 1, 147-161.

Murphy, K., \& Gordon, M. (2006). Assessment of adults with ADHD. In R. A.Barkley (Ed.), Attentiondeficit/hyperactivity disorder: A handbook of diagnosis and treatment (3rd ed., pp. 425-452). New York, NY: Guilford Press.

Nigg, J. T. (2005). Neuropsychologic theory and findings in attention-deficit/hyperactivity disorder: The state of the field and salient challenges for the coming decade. Biological Psychiatry, 57, 1424-1435.

10.1016/j.biopsych.2004.11.011 
Pella, R. D., Hill, B. D., Shelton, J. T., Elliott, E., \& Gouvier, W. D. (2012). Evaluation of embedded malingering indices in a non-litigating clinical sample using control, clinical, and derived groups. Archives of Clinical Neuropsychology, 27, 45-57. 10.1093/arclin/acr090

Quinn, C. A. (2003). Detection of malingering in assessment of adult ADHD. Archives of Clinical Neuropsychology, 18, 379-395. 10.1016/S0887-6177(02)00150-6

Rios, J., \& Morey, L. (2013). Detecting feigned ADHD in later adolescence: An examination of three PAI negative distortion indicators. Journal of Personality Assessment, 95, 594-599.

Root, J., Robbins, R., Chang, L., \& van Gorp, W. (2006). Detection of inadequate effort on the California Verbal Learning Test (2nd ed.): Forced choice recognition and critical item analysis. Journal of the International Neuropsychology Society, 12, 688-696.

Salthouse, T. (1994). The aging of working memory. Neuropsychology, 8, 535-543. 10.1037/0894-4105.8.4.535

Schroeder, R., \& Marshall, P. (2010). Validation of the sentence repetition test as a measure of suspect effort. The Clinical Neuropsychologist, 24, 326-343.

Slick, D. J., Sherman, E. M., \& Iverson, G. L. (1999). Diagnostic criteria for malingered neurocognitive dysfunction: Proposed standards for clinical practice and research. Clinical Neuropsychologist, 13, 545561. 10.1076/1385-4046(199911)13:04;1-Y;FT545

Sollman, M. J., Ranseen, J. D., \& Berry, D. T. (2010). Detection of feigned ADHD in college students. Psychological Assessment, 22, 325-335. 10.1037/a0018857

Stefanatos, G. A., \& Baron, I. S. (2007). Attention-deficit/hyperactivity disorder: A neuropsychological perspective towards DSM-V. Neuropsychology Review, 17, 5-38. 10.1007/s11065-007-9020-3

Strauss, E., Sherman, E. M. S., \& Spreen, O. (2006). A compendium of neuropsychological tests: Administration, norms, and commentary. New York: Oxford University Press.

Suhr, J., Buelow, M., \& Riddle, T. (2011). Development of an infrequency index for the CAARS. Journal of Psychoeducational Assessment, 29, 160-170.

Suhr, J., Hammers, D., Dobbins-Buckland, K., Zimak, E., \& Hughes, C. (2008). The relationship of malingering test failure to self-reported symptoms and neuropsychological findings in adults referred for ADHD evaluation. Archives of Clinical Neuropsychology, 23, 521-530. 10.1016/j.acn.2008.05.003

Suhr, J. A., Sullivan, B. K., \& Rodriguez, J. L. (2011). The relationship of noncredible performance to continuous performance test scores in adults referred for attention-deficit/hyperactivity disorder evaluation. Archives of Clinical Neuropsychology, 26, 1-7. 10.1093/arclin/acq094

Sullivan, B. K., May, K., \& Galbally, L. (2007). Symptom exaggeration by college adults in attention-deficit hyperactivity disorder and learning disorder assessments. Applied Neuropsychology, 14, 189-207. 10.1080/09084280701509083

Tan, J. E., Slick, D. J., Strauss, E., \& Hultsch, D. (2002). How'd they do it? Malingering strategies on symptom validity tests. The Clinical Neuropsychologist, 16, 495-505.

Tucha, L., Sontag, T. A., Walitza, S., \& Lange, K. W. (2009). Detection of malingered attention deficit hyperactivity disorder. Attention Deficit and Hyperactivity Disorders, 1, 47-53. 10.1007/s12402-0090007-1

U.S. Drug Enforcement Administration, Office of Diversion Control. (2012). National Forensic Laboratory Information System special report: ADD/ADHD stimulants in NFLIS, 007-2011. Springfield, VA: U. S. Drug Enforcement Administration.

Van Dyke, S. A., Millis, S. R., Axelrod, B. N., \& Hanks, R. A. (2013). Assessing effort: Differentiating performance and symptom validity. The Clinical Neuropsychologist, 27, 1234-1246. 10.1080/13854046.2013.835447

Victor, T. L., Boone, K. B., Serpa, J. G., Buehler, J., \& Ziegler, E. A. (2009). Interpreting the meaning of multiple symptom validity test failure. The Clinical Neuropsychologist, 23, 297-313.

10.1080/13854040802232682

Wechsler, D. (2008a). Wechsler Adult Intelligence Scale (4th ed.). San Antonio, TX: The Psychological Corporation.

Wechsler, D. (2008b). Wechsler Memory Scale (4th ed.). San Antonio, TX: The Psychological Corporation. 
Wetzell, L., \& Boll, T. (1991). Short Category Test, booklet format. Los Angeles, CA: Western Psychological Services.

Weyandt, L., \& DuPaul, G. (2013). College Students with ADHD. New York, NY: Springer. 10.1007/978-1-46145345-1

White, T., \& Stern, R. (2003). Neuropsychological Assessment Battery. Lutz, FL: Psychological Assessment Resources, Inc.

Wilens, T., Biederman, J., Faraone, S., Martelon, M., Westerberg, D., \& Spencer, T. (2009). Presenting ADHD symptoms, subtypes, and comorbid disorders in clinically referred adults with ADHD. Journal of Clinical Psychiatry, 70, 1557-1562.

Williamson, K. D., Combs, H. L., Berry, D. T., Harp, J. P., Mason, L. H., \& Edmundson, M. (2014). Discriminating among ADHD alone, ADHD with a comorbid psychological disorder, and feigned ADHD in a college sample. The Clinical Neuropsychologist, 28, 1182-1196. 10.1080/13854046.2014.956674

Young, J. C., \& Gross, A. M. (2011). Detection of response bias and noncredible performance in adult attentiondeficit/hyperactivity disorder. Archives of Clinical Neuropsychology, 26, 165-175. 10.1093/arclin/acr013 